\title{
ANALISIS OF INPUT IMPEDANCE OF THE TRACTION VEHICLE WITH DC CHOPPER AS A FUNCTION OF OPERATION MODE
}

A problem of analysis of the input impedance of a converter traction vehicle is presented in the paper. The value of input impedance of a traction vehicle has significant influence of compatibility between track circuits and traction vehicles. The model of chopper controlled DC series motor vehicle was implemented as a simulation model including all significant parameters of the whole system: substation-catenary-input filter-chopper. Exemplary results of analysis of the specific locomotive EM10 are included. The results both of analytical and simulation approach for low frequency input impedance computations were compared.

\section{Introduction}

Dynamic development of semiconductor technology in the seventies was the main cause of high-power converters prevalence in traction vehicles. Initially DC-DC converters were most popular and effective in reducing energy losses during DC series motors starting (so called: second generation traction drive). At the beginning thyristor technology was applied while expansion of transistor devices provided possibility of common use of the AC motors fed with inverters (third generation of traction drives) both with $\mathrm{DC}$ and $\mathrm{AC}$ power supply systems. Asynchronous motors have significant advantages comparing with DC motor in the aspect of construction and maintenance. However, the main part of traction vehicles used in Poland, applied „conventional“ vehicles with DC series motors and rheostatic control (first generation of traction drive). So the possible solutions to modernize rolling stock fleet in Poland are: re-engineering old vehicles or exchanging them to completely new ones. The decision which option is to be chosen, must be based on results of both technical and financialeconomic analysis.

The easiest way of reengineering old traction vehicles when DC motors will be kept is to equip them with chopper systems which will reduce energy consumption during starting and allow regeneration of energy during braking. However chopper-controlled vehicles generate harmonics in current taken from catenary, so compatibility aspects of traction system with signaling and command-control systems are to be taken into account when reengineered vehicles are to be put into service on lines when previously only vehicles with first-generation of drive were used. So in most of the countries, limits of certain harmonics in a vehicle's current were imposed in order to protect track circuits against disturbances. An example of limits being in law at the Polish State Railways [9] are presented in Fig. 1.
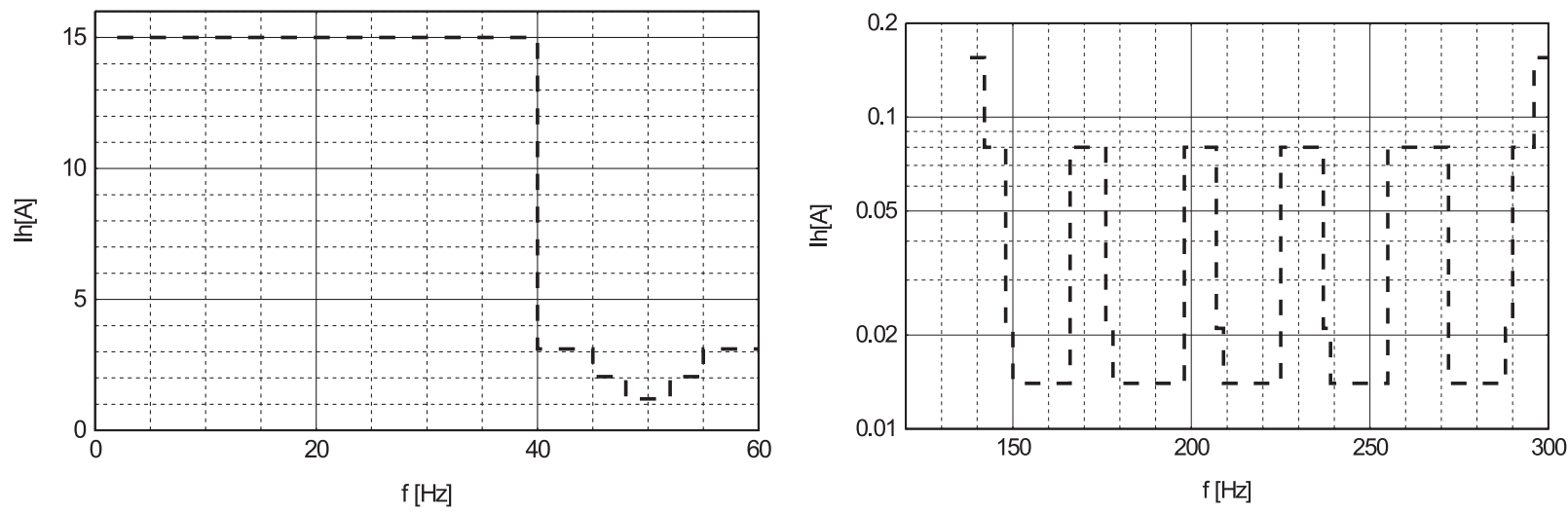

Fig. 1 Limits of harmonics in input vehicle's current

\footnotetext{
* Adam Szeląg ${ }^{1}$, Marcin Steczek ${ }^{2}$

${ }^{1}$ Electric Traction Division, Faculty of Electrical Eng., Warsaw Univ. of Technology, Warsaw, Poland, E-mail: aszelag@nov.iem.pw.edu.pl

${ }^{2}$ Faculty of Electrical, Electronic, Computer and Control Engineering, Technical University of Lodz, E-mail: msteczek@p.lodz.pl,
} 
One of the parameters, which determinate a degree of possible disturbance propagation from the power supply system to track circuits is the traction vehicle's input impedance Zin. Predictable is the fact that in case of a vehicle with converter this impedance may vary and be dependent on parameters of the input filter of the vehicle, frequency and chopper mark-period ratio. This problem was discussed in literature [1], while the following paper presents a simulation method of calculation of low frequency, converter traction vehicle input impedance for a specific vehicle. The object of simulations was a modernized traction vehicle equipped with a power step-down chopper with DC series motors drive.

The influence of the supply line, substation filters, parameters and failure states of the converter were also considered.

\section{Methods of analysis}

For the purposes of verification of the results of computer simulations were compared with analytical calculations. The analytical formula for input impedance was derived with the assumptions discussed in [1]

When one assumes that the input and output powers of the converter are equal (efficiency=1), one- phase chopper (Fig. 2a) load impedance is given by:

$$
Z_{c}=\frac{Z_{1}}{k^{2}} .
$$

where: $Z_{c}$ - chopper load impedance, $Z_{1}$ - static load impedance, $k$ - chopper mark-period ratio (simple control- as ratio: on time to period).

With this assumption, one-phase chopper input impedance $Z_{\text {in } 1}$ is given by:

$$
Z_{i n 1}(j \omega)=R_{f}+j \omega L_{f}+\frac{R_{l}+j \omega L_{l}}{k^{2}-\omega^{2} L_{l} C_{f}+j \omega C_{f} R_{l}}
$$

The similar approach is applied for a two-phase chopper (Fig. $2 b)$. In this case the chopper load impedance is given by: $Z_{c}=$ $=Z_{c 1} / 2=Z_{l} / 2 k^{2}$ where $Z_{c 1}$ is the impedance of a single converter load. Finally two-phase chopper input impedance $Z_{i n 2}$ is given by:

$$
Z_{i n 2}(j \omega)=R_{f}+j \omega L_{f}+\frac{R_{l}+j \omega L_{l}}{2 k^{2}-\omega^{2} L_{l} C_{f}+j \omega C_{f} R_{l}}
$$

A verification of this analytical approach based on the above equations (1)-(2) was carried out with the results of the simulation method, where the input impedance $Z_{i n}$ of a chopper equipment was calculated using a theoretical circuit model (Fig. 2).
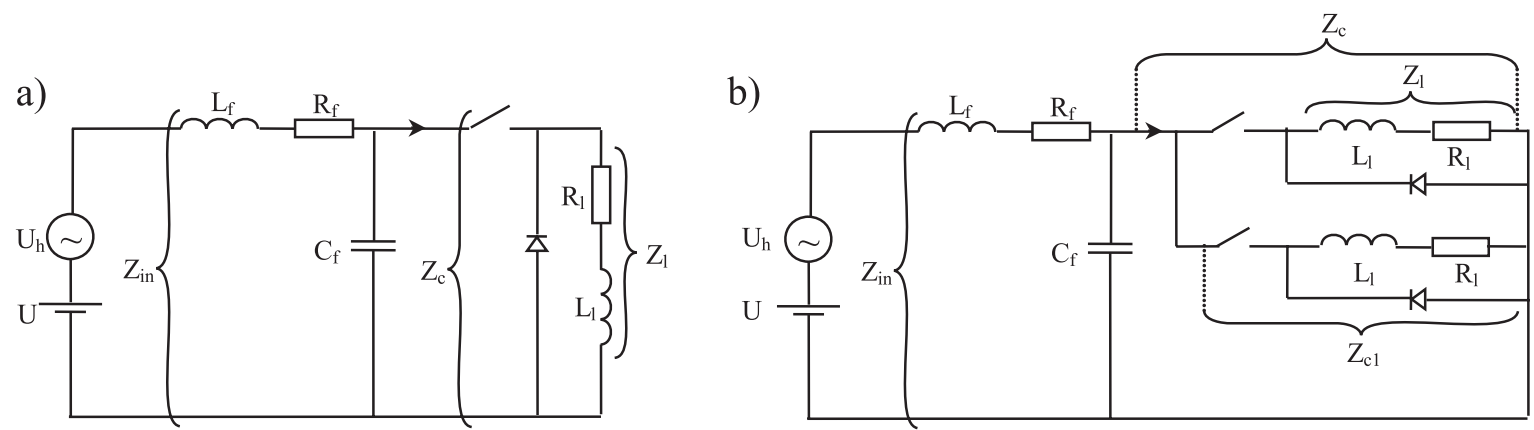

Fig. $2 \mathrm{~A}$ scheme of a circuit for a chopper input impedance $Z_{\text {in }}$ calculation a) one-phase chopper b) two-phase chopper

substation

catenary

vehicle

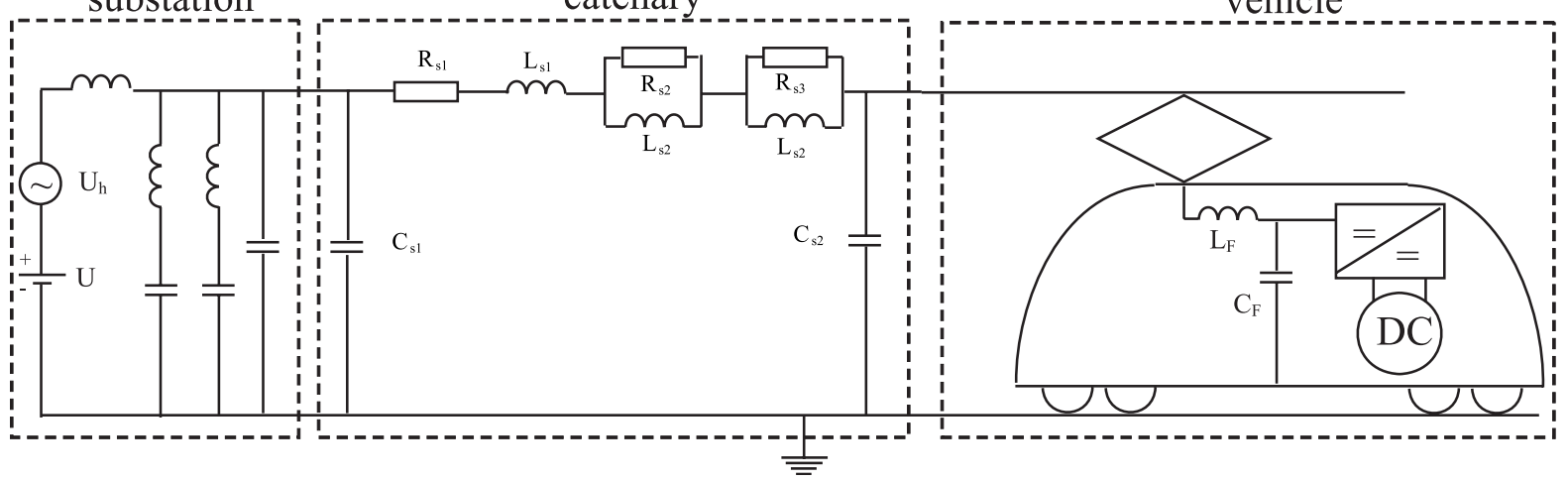

Fig. 3 Simulation model of the whole system for a input impedance calculation 


\section{Simulation model}

The model of EM10 traction vehicle main circuit was implemented as a simulation model. The model of a chopper - controlled DC series motor proposed in [3] was used with adequate assumptions. Moreover excitation winding inductance was implemented as dynamic inductance given by $L(I)=Z \frac{d \Phi(I)}{d I}$

where: $Z$ is the number of excitation winding coils and $\Phi$ is a main flux of the machine. The eddy current circuit decreases flux pulsations, such an effect was observed in chopper-controlled motors. The switching strategy was specified assuming the maximum start-up current of 320 A for a single motor group, with the constant operating frequency. The model of a catenary proposed in [2] was considered in the calculations.

Additionally an eddy currents circuit and smoothing inductance were modeled. The eddy currents phenomena is caused by current pulsations during chopper drive control and causes stray load losses in solid parts of the motor magnetic circuit. This results in reduction of motor efficiency. Transistor choppers are operating at $400 \mathrm{~Hz}$, the analysed scheme of the vehicle is presented in Fig. 4.

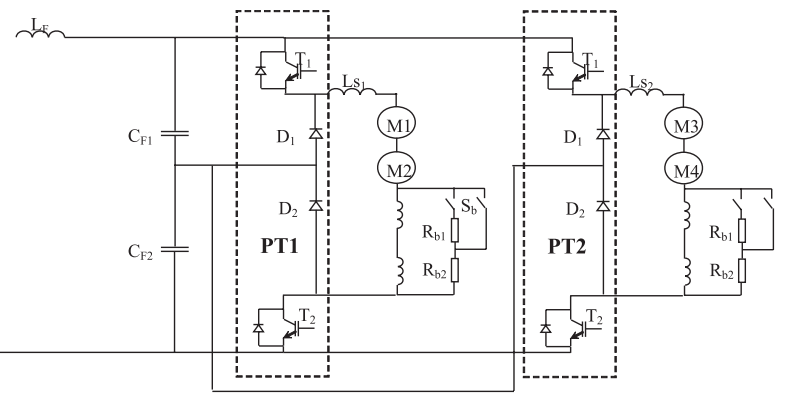

Fig. $4 \mathrm{~A}$ scheme of the analysed vehicle

\section{Simulation results}

The input impedance was computed using a simulation tool in time domain with FFT option. In input impedance calculations following aspects were taken into consideration: influence of catenary, substation filters (for 6- and 12-pulse rectifier), failure states of the converter (variant phase shifts between converters or different individual chopper operating frequencies), operation of two vehicles on the line. The most interesting results were observed at frequencies close to the input filter resonant frequency $(\sim 22 \mathrm{~Hz})$. The parameters of the input filter ( $L=18 \mathrm{mH}, C=2.8 \mathrm{mF}$ ) compared with DC motor parameters [4] were significant for the results. The most important for low-frequency track circuit disturbances is $50 \mathrm{~Hz}$ frequency. The results of simulations did not find disturbing currents in this range. In many available in literature articles on chopper-controlled DC motor simulations authors omitted influ- ence of eddy currents. However, the damping influence of eddy currents on the input impedance was observed from the results of simulations (Fig. 5). Fig. 6 shows a variation of the input imped-

a)

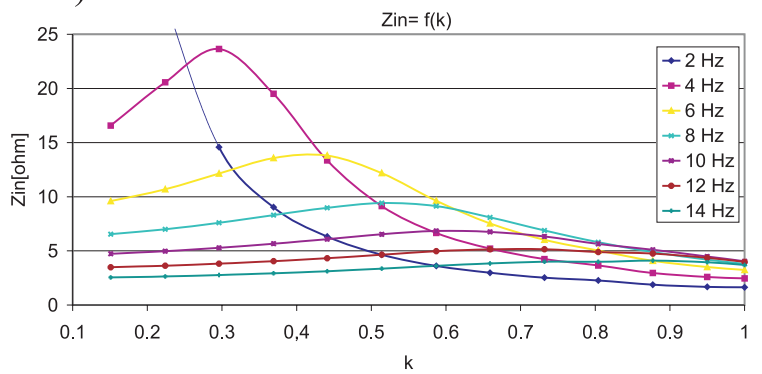

b)

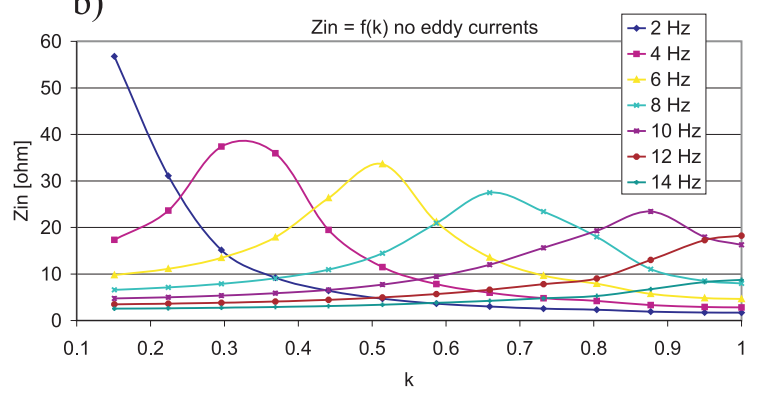

Fig. 5 Variation of low frequency input impedance with chopper mark-period ratio

a) including eddy currents influence b) eddy current influence omitted

a)

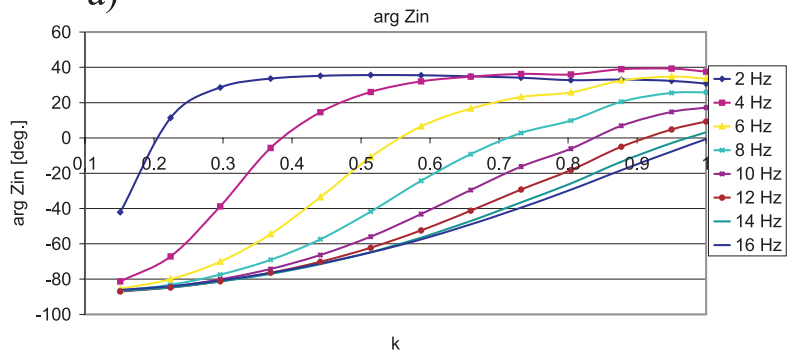

b)

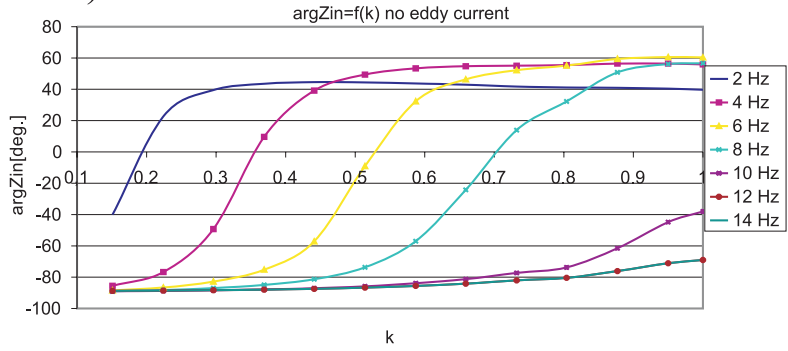

Fig. 6 Variation of low frequency input impedance phase with chopper mark-period ratio

a) including eddy currents influence

b) eddy current influence omitted 
ance phase with $\mathrm{k}$ for low frequencies. It is shown that the vehicle can change its load character with a mark period from inductive to capacitive. Eddy currents have also significant influence on such changes.

a)

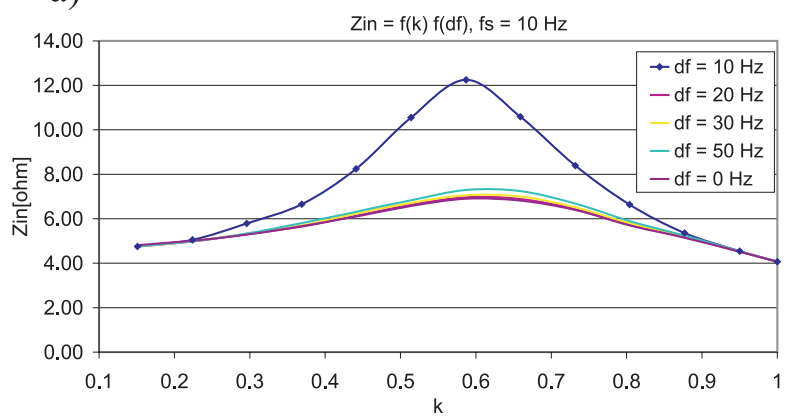

b)

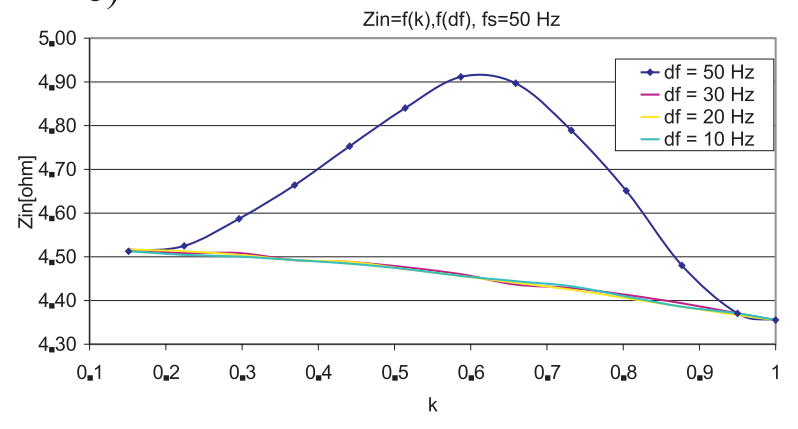

Fig. 7 Variation of low frequency input impedance with chopper markperiod ratio for different frequency of converters; difference equal $d f a$ ) Zin impedance for $10 \mathrm{~Hz}$ b) Zin impedance for $50 \mathrm{~Hz}$

The influence of operating frequency difference between individual choppers on the input impedance was carried out. Fig. 7 shows variation of the input impedance with a chopper mark period and with difference between operating frequencies (df). The influence is significant for frequencies equal to $\mathrm{df}$.

\section{Conclusions}

The input impedance analysis with usage of the derived model for the specific vehicle with chopper-controlled motors and the influence of substation filters, length of supply line and parameters of vehicle filter were analyzed brought the following conclusions:

- the most significant input impedance variations can be observed for frequencies near the input filter resonant frequency (in this case it is $22 \mathrm{~Hz}$ ),

- $50 \mathrm{~Hz}$ input impedance of the analysed vehicle is practically constant with a chopper mark-period ratio,

- as $50 \mathrm{~Hz}$ current limit is $1,25 \mathrm{~A}$ [Fig. 1] it means (for the calculated input impedance) that if $50 \mathrm{~Hz}$ voltage at the vehicle's pantograph is below $5,6 \mathrm{~V}$ this current limit will not be exceeded; typically $50 \mathrm{~Hz}$ voltage component at DC side voltage of $3 \mathrm{kV}$ DC traction substation with bridge 6-pulse or 12-pulse rectifiers is much lower,

- a supply current pulsation reaches its maximum for $k=0.25$ and 0.75 for a two - phase chopper with 180 degree phase-shift,

- the operation of two vehicles supplied from one substation had no disturbing influence on track circuits,

- the offset value (nominal 180 degree) does not affect the input impedance variations,

- eddy currents phenomena significant for the value of input impedance of a chopper- controlled DC series motor, however the analytical method based on eq. (1)-(2) does not take it into account,

- analytical and simulation methods of analysis of the input impedance of a chopper-controlled R L static load give similar results, but the analytical method may be used only for low frequency,

- for high frequencies (above the operation frequency of a chopper) in order to calculate input impedance of a vehicle simulation methods are to be used.

\section{Reference}

[1] MELLITT, B., TAUFIQ, J. A., XIAOPING, J.: Input impedance of chopper equipment and its significance in low-frequency track circuits, IEEE PROCEEDINGS, vol. 136, Pt. B, No. 1/1989,

[2] SZELĄG, A.: Problems of analysis and design of DC electric traction system with application of modelling and simulation technique (in Polish), Warsaw University of Technology Press, Warsaw, 2002,

[3] Power electronics in electric traction. Selected problems of electrotechnics (in Polish), Symposium - Institute of Electrotechnics, Warsaw, 1973,

[4] GIZINSKI, P.: Transistor IGBT control system of EM10 locomotive (3000 - 1 MW) - (in Polish), Technika Transportu Szynowego, pp. $30-35,6 / 2004$,

[5] JABLONSKI, M.: D.C. machines, Script for Technical University of Lodz, Lodz, 1973,

[6] GOGOLEWSKI, Z., GABRYŚ, W.: D.C. machines, constructions, construction, special issues, PWT Warsaw, 1960,

[7] Power electronics in electric D.C. traction - pulse control, The Polish Academy of Science, Polish Scientific Publishers, Warsaw 1976,

[8] SZELAG, A., ZAJAC, W: Harmonic distortion caused by suburban and underground rolling stock with D.C. motors, CIEP 96, Cuernavaca, Mexico, 1996,

[9] BIALON, A: Accepted parameters of disturbances for signalling and control systems and traction vehicles (in Polish), $6^{\text {th }}$ International Conference MET 2003 Warsaw, September 25-27, 2003. 